\title{
ATUAÇÃO DO EGRESSO DO CURSO DE CIÊNCIAS CONTÁBEIS DA UNEMAT - CAMPUS DE TANGARÁ DA SERRA NO MERCADO DE TRABALHO
}

\author{
Luciene Pereira Viana ${ }^{1}$ \\ Laércio Juarez Melz ${ }^{2}$ \\ Josiane Silva Costa dos Santos ${ }^{3}$ \\ Eugênio Carlos Stieler ${ }^{4}$
}

\section{RESUMO}

$\mathrm{Na}$ atualidade o mercado exige cada vez mais profissionais capacitados, e que estejam em busca de conhecimento técnico e cientifico. Este projeto de pesquisa tem como finalidade demonstrar se os bacharéis em contabilidade estão inseridos no mercado de trabalho. Para obter as informações, foi aplicado questionário contendo vinte e sete perguntas que foram enviados para 180 egressos do curso de Ciências Contábeis da UNEMAT - Campus de Tangará da Serra obteve um retorno de 74, que formou no período de 2005 a 2011. Com resultados foram identificados à situação atual dos concluintes: Área de atuação, Perspectivas na área profissional, as principais dificuldades encontradas na contratação, mercado de trabalho e remuneração. Foi concluído através da pesquisa que $67,57 \%$ dos entrevistados trabalham em instituições privadas. Identificou-se que a falta de experiência é a principal dificuldade encontrada na contratação. Quanto à área profissional os egressos responderam que a maioria tem boas perspectivas em relação ao curso.

Palavras-chave: Qualificação profisssional. Área de atuação. Contabilidade. Ensino de Contabilidade

\section{INTRODUÇÃO}

O presente tema foi escolhido a fim de verificar a situação profissional do acadêmico formado em Ciências Contábeis da UNEMAT - Campus de Tangará da Serra. Para a IES (Instituição de Ensino Superior) é importante analisar se está cumprindo os objetivos propostos para formar um profissional qualificado com diferencial para o mercado de trabalho. O traçado do perfil do egresso de qualquer curso superior é de fundamental importância para a compreensão daquilo que se é esperada do estudante ao longo de sua trajetória pela Instituição de Ensino Superior - (IES). No Projeto Pedagógico dos cursos é estabelecido o perfil do profissional que se deseja formar a partir do potencial dos ingressantes, do desenvolvimento das habilidades acadêmicas, buscando alcançar as

\footnotetext{
1 Acadêmica do curso de Ciências Contábeis da UNEMAT - Campus de Tangará da Serra, e-mail: lucienevianatga@gmail.com

${ }^{2}$ Mestre em Engenharia de Produção (UFSCar), Professor do curso de Ciências Contábeis da UNEMAT Campus de Tangará da Serra, e-mail: laercio@unemat.br

${ }^{3}$ Contadora, Professora do curso de Ciências Contábeis da UNEMAT - Campus de Tangará da Serra.

${ }^{4}$ Mestre em Ensino de Física e Matemática (UNIFRA), Professor do curso de Ciências Contábeis da UNEMAT - Campus de Tangará da Serra.
} 
competências profissionais necessárias para o exercício da profissão. Esse delineamento é de extrema importância, pois é a partir do perfil do profissional que deseja formar que se estabelecem as competências profissionais de uma área e esse perfil ideal deve estar claramente descrito no projeto pedagógico do curso (BRITO, 2008).

O mundo atual exige do profissional um conhecimento que transcende a técnica, busca um profissional com competências para entender o negócio, visando orientar o gestor e participar das decisões de forma consciente. Dessa forma, recai para os profissionais a exigência de um novo perfil, mais condizente com a atual dinâmica assumida pelas organizações (LEAL, SOARES e SOUZA, 2008).

Com as exigências do mercado de trabalho e a falta de informações da Universidade surgiu ideia de pesquisar a situação atual dos egressos, é o que o presente artigo tem como objetivo analisar as áreas de atuação do curso de Ciências Contábeis, e estudar quais destas áreas os formandos da UNEMAT - Campus de Tangará da Serra estão ingressado. Como objetivos específicos: a) verificar as perspectivas dos egressos quanto à sua formação de graduação e pós-graduação; b) analisar condição profissional dos egressos antes e depois da conclusão do curso; c) conhecer as principais dificuldades enfrentadas ao final do curso.

\section{REFERENCIAL TEÓRICO}

\subsection{Conceito de Contabilidade}

Segundo Sá (2002, p. 46) "Contabilidade é a ciência que estuda os fenômenos patrimoniais, preocupando-se com realidades, evidências e comportamentos dos mesmos, em relação à eficácia funcional das células sociais."

Conforme Marion (2002, p. 25):

A contabilidade pode ser estudada de modo geral (para todas as empresas) ou particular (aplicada a certo ramo de atividade ou setor da economia). Quando estudada de forma genérica, a contabilidade é denominada contabilidade geral ou contabilidade financeira. Quando aplicada a um ramo especifico, normalmente é denominada de acordo com a atividade daquele ramo.

A contabilidade tem por finalidade precípua de promover os meios informativos e de controle com o intuito de coletar os dados ocorridos na empresa que possam ter impactos e causar variações em sua posição patrimonial. A contabilidade é o instrumento de medição e avaliação do patrimônio e dos resultados auferidos pela gestão da administração da empresa (ATTIE, 1998). 
Atuação do egresso do curso de Ciências Contábeis da UNEMAT - campus de Tangará da Serra no mercado de trabalho

Luciene Pereira Viana, Laércio Juarez Melz, Josiane Silva Costa dos Santos, Eugênio Carlos Stieler

O objetivo da contabilidade, conforme Marion (2002) é trazer informações que irão influenciar diretamente nas tomadas de decisões dentro de uma organização. Direcionando quais os caminhos corretos e seguros que empresa deve seguir, preservando seu próprio patrimônio.

\subsection{Histórico da Contabilidade no Brasil}

O Conselho de Regional de Contabilidade (CRC) destaca que a Escola de Comércio do Rio de Janeiro foi à primeira escola de Contabilidade no Brasil reconhecida pelo decreto 1.339 de 09/01/1905 e dava ao aluno concluinte o diploma de guarda-livros e perito judicial. Com o decreto de $\mathrm{n}^{\circ} 8.191$ de 20/11/1945 muda a denominação de guarda-livros para Técnico em Contabilidade. Sendo o primeiro curso superior em Ciências Contábeis criado pelo decreto $n^{\circ} 7.988$ de 22/09/1945.

O ensino superior de contabilidade no Brasil evoluiu com base no ensino comercial, com as mudanças ocorridas hoje o profissional tem que ter habilidades para lidar com a legislação não só de uma forma técnica, mas que tenha uma formação gerencial capaz de liderar equipes e tomar decisões (FIGUEIREDO E FABRI 2000).

\subsection{A profissão contábil}

A contabilidade existe desde 4.000 a. C. O homem primitivo utilizava-se de desenhos e figuras para controlar e preservar seu patrimônio, antes mesmo que desenvolvesse a matemática ou a escrita (IUDÍCIBUS; MARION, 2002).

Segundo Dias, Rodrigues e Ferreira (2011), as constantes transformações, inovações e novas tecnologias nas áreas política, social, econômica, tecnológica e cultural, exigem do profissional estar atento ás mudanças, para fazer delas inspirações na busca de novos conhecimentos e tornar isso o diferencial para alcançar uma posição mais elevada no mercado.

A Contabilidade tem papel fundamental dentro de uma empresa, para isso o profissional da área contábil deve aperfeiçoar seus conhecimentos e não se limitar ao desempenhar sua função dentro do campo de atuação, com a realização de um bom trabalho, o profissional passa a ser bem visto pela sociedade conquistando a confiança dos empresários (SOCZEK, 2010).

Figueiredo e Fabri (2000, p. 24) destacam que o perfil do profissional da contabilidade deve incluir:

[...] o domínio da linguagem dos negócios, pois é o responsável pelo ambiente de geração de informações fundamentais ao processo decisório e estratégico das organizações. Caracteriza-se como um profissional crítico, ético e lúcido, solidamente 
capacitado para planejar, organizar, liderar e dirigir as atividades de controle do gerenciamento contábil das empresas.

Marion (2005) sugere que o contador deve ser o profissional mais bem informado de toda empresa, pois sua atuação exige que conheça as operações realizadas, faça seu registro e apresente as informações resultantes do processo contábil na forma de relatórios para administração da empresa, afim de que esta possa tomar decisões. As decisões tomadas, por sua vez, podem ocasionar retornos positivos ou negativos para a empresa e influenciar quem dela depende, nessas circunstâncias, o contador assume verdadeiramente uma responsabilidade social.

O profissional contábil entre suas responsabilidades deve gerar informações de todas as operações realizadas dentro da empresa, mostrando se as decisões tomadas foram corretas ou não, além disso, deve estar preparado para atender as necessidades de uma sociedade cada vez mais exigente (SOCZEK, 2010).

No mundo atual o profissional contábil tem que estar disposto a manter-se atualizado e aperfeiçoar-se de acordo com as necessidades do mercado só assim conseguira enfrentar as pressões e desafios constantes. Conflitos de demanda, solicitações inesperadas, coincidências de prazo para entrega dos serviços, são situações que o profissional tem de estar preparado para manter o controle, isso requer habilidade para selecionar e assumir prioridades dentro das limitações de tempo e recursos (MARION, 1996).

Dias e Moreira (2008), procura-se formar profissionais, que não só saibam aplicar a legislação e linguagem contábil na confecção de relatórios, mas que tenham uma formação gerencial capaz de capacitá-lo a tomar decisões e liderar equipes de trabalho. Porém, o que se observa no processo de ensino aprendizagem é a ênfase na reprodução dos conhecimentos já existentes, conduzindo a limitação à criação e inovação, ou seja, não estimulando os alunos a construírem conhecimento e transformá-los em saber.

\subsection{Campos de atuação do profissional contábil}

Marion (2009, p. 29) afirma que [...] "a contabilidade é uma das áreas que mais proporcionam oportunidades para o profissional. O estudante que optou por um curso superior de contabilidade terá inúmeras alternativas."

O profissional contábil deve sempre buscar crescimento dentro da área, se especializando para que possa alcançar mais espaço no mercado de trabalho. Por meio de uma visão geral, observa-se que o campo de atuação do profissional contábil no mercado é bem extenso (CAVALCANTE, 2009). 
A profissão contábil é uma das áreas de maior crescimento e que mais proporciona oportunidades para o profissional. O egresso do curso superior de contabilidade terá inúmeras alternativas (MARION 2005).

De acordo com Marion (2009), o contador pode atuar em quatro áreas: na empresa, independente (autônomo), no ensino e em órgãos públicos. Na empresa pode atuar como Planejador Tributário, Analista Financeiro, Contador Geral, Cargos Administrativos, Auditor Interno, Contador de Custo, Contador Gerencial, Atuário. Como independente ou autônomo nas áreas de Auditor Independente, Consultor, Empresário contábil, Perito Contábil, Investigador de Fraude. No Ensino como Professor, Pesquisador, Escritor, Parecerista, Conferencista e como Órgão Publico nos cargos de Contador Público, Agente Fiscal de Renda, Diversos Concurso Públicos, Tribunal de Contas e Oficial Contador.

Das diversas áreas citadas acima, pode-se conceituar as que mais se destacam no mercado de trabalho, como Contador segundo Marion (2009, p. 29) [...] "é o profissional que exerce as funções contábeis, com formação superior de ensino Contábil (Bacharel em Ciências contábeis)."

Auditor Contábil pode-se definir de forma simples como o levantamento das transações, procedimentos, operações, rotinas e das demonstrações financeiras de uma entidade, compreende o exame de documentos, livros e registros, inspeções e obtenção de informações e confirmações, objetivando mensurar a exatidão desses registros e das demonstrações contábeis delas decorrentes (CREPALDI, 2002).

Analista Financeiro [...] "analisa a situação econômico-financeira da empresa por meio de relatórios fornecidos pela Contabilidade. A análise pode ter os mais diversos fins: medida de desempenho, concessão de crédito, investimentos" (Iudícibus e Marion 2002, p. $45)$.

O contador em cargos administrativos pode atuar em cargos de assessoria, funções de chefia, de gerência e, até mesmo, de diretoria, com sucesso adquirido, por ter conhecimento a respeito do resultado gerado pelas decisões tomadas (GIRARDI, 2009).

Perito contábil de acordo com Alberto (2002, p.19) [...] "perícia é um instrumento especial e constatação, prova ou demonstração, científica ou técnica, da veracidade de situações, coisas ou fatos."

Consultor Contábil Iudícibus e Marion (2002) diz que a consultoria contábil não se restringe apenas á parte contábil e financeira, mas também á consultoria fiscal Imposto de Renda, IPI, ICMS e outros, na área de processamentos de dados, comércio exterior. 
Professor de Contabilidade "exerce o magistério de $2^{\circ}$ grau ou de faculdade (neste caso há necessidade de pós-graduação), não só na área Contábil, como também em cursos de Ciências Econômicas, de Administração" (IUDÍCIBUS E MARION 2002, p. 45).

Pesquisador contábil para Marion (2009) o pesquisador contábil é para aqueles que optaram pela carreira universitária, há um campo pouco explorado no Brasil, ou seja, a investigação cientifica na contabilidade.

Cargos Públicos para Rosa (2011, p. 6) "a contabilidade aplicada ao Setor Público é o ramo da ciência contábil que aplica, no processo gerador de informações, os Princípios da Contabilidade e as normas contábeis direcionadas ao controle patrimonial de entidades do setor público."

\subsection{UNEMAT - Universidade do Estado de Mato Grosso}

Com base na Lei 703, foi publicado na Cidade de Cáceres o Decreto Municipal 190, Criando o Instituto de Ensino Superior de Cáceres (IESC), vinculado a Secretaria Municipal de Educação e à Assistência Social, passando a funcionar como Entidade Autárquica Municipal em 15 de agosto de 1978 (UNEMAT, 2012).

Após várias alterações na Legislação alterando sua denominação, em 15 de Dezembro de 1993, através da Lei Complementar 30, institui-se a Universidade do Estado de Mato Grosso (Unemat), mantida pela Fundação Universidade do Estado de Mato Grosso (Funemt), sendo credenciada pelo Conselho Estadual de Educação em 10 de agosto de 1999. (UNEMAT, 2012).

Campus Universitário de Tangará da Serra (2008), em Abril de 1995, o Ensino Superior Privado (CESUT), fora empossada pela UNEMAT, sendo mantidos os cursos de Graduação em Administração, Ciências Contábeis e Letras, que já existiam desde 1990 através da CESUT, conforme aprovação do Conselho Estadual de Educação de Mato Grosso através do Parecer $n^{\circ}$ 036/95. Sendo implantados futuramente os cursos de graduação em Agronomia (2001), Ciências Biológicas (2001), Enfermagem (2006) (UNEMAT, 2012).

Campus Universitário de Tangará da Serra (2008), diz que Curso de Ciências Contábeis, iniciou suas atividades, conforme Autorização de Funcionamento, através do Decreto N. ${ }^{\circ}$ 99.023, de 05 de março de 1990 (CIÊNCIAS CONTÁBEIS, 2012).

Em 1998, foi encaminhado processo para Reconhecimento de Curso, protocolado sob n. ${ }^{\circ}$ 204/98 no Conselho Estadual de Educação (CEE), cujo Parecer n. ${ }^{\circ}$ 199/98 foi aprovado em sessão plenária de 29/09/98. O reconhecimento do curso de Ciências Contábeis foi 
concedido através da Portaria n. ${ }^{\circ}$ 875/98 SEDUC/ MT, datado de 19/10/1998, publicado no Diário Oficial no dia 23/10/98, página 09 (CIÊNCIAS CONTÁBEIS, 2012).

O Curso de Ciências Contábeis, do Campus Universitário de Tangará da Serra, tem como objetivo formar contadores capacitados e qualificados ao exercício profissional, dotados de senso analítico crítico, comprometido com os valores cristãos de nossa sociedade, e a missão da instituição, com o objetivo de contribuir para o desenvolvimento das sociedades, com a competência técnica acadêmico desta profissão, e como objetivos específicos proporcionar visão ampla e abrangente dos sistemas de informações contábeis e gerenciais, capazes de compreender, analisar e processar essas informações, incentivar o aluno a agir dentro dos princípios éticos, morais e legais, promovendo o bom relacionamento humano, proporcionar formação profissional dotada de competências e habilidades que viabilizem aos agentes econômicos e seus propostos o pleno cumprimento de responsabilidade perante a sociedade (CIÊNCIAS CONTÁBEIS, 2012).

\section{METODOLOGIA}

O presente artigo tem como fonte de pesquisa os egressos do curso de Ciências Contábeis da UNEMAT, Campus de Tangará da Serra entre os anos de 2005 a 2011. Quanto aos procedimentos trata-se de pesquisa bibliográfica, com base em livros, internet, revistas, artigos científicos já publicados sobre o tema para a realização do referencial teórico. Silva (2010, p. 54) diz que "a bibliografia constitui um ramo auxiliar da ciência, pois permite encontrar fontes, os livros e os materiais científicos pertinentes para a concretização do trabalho científico."

Para a realização do artigo se fez necessário à utilização de levantamento de dados. De acordo com Both et al (2007, p. 99)

o levantamento se caracteriza pela abordagem direta do pesquisador com os sujeitos da pesquisa, com o objetivo de colher informações. Basicamente, procede-se a solicitação de informações a um grupo significativo de pessoas acerca do problema estudado.

Quanto às técnicas de pesquisa para o levantamento dos dados foi de caráter qualitativo através da aplicação de questionário aos egressos formados nos anos de 2005 a 2011, para que a pesquisa obtivesse embasamento foi elaborado em 2 etapas. A $1^{\text {a }}$ foi obter informações como nome, e-mail e telefone e ano de conclusão, estes dados foram coletados junto ao Departamento de Supervisão de Apoio Acadêmico da UNEMAT localizado no Campus de Tangara da Serra e a $2^{\mathrm{a}}$ com os concluintes do curso no qual foi aplicado um 
Atuação do egresso do curso de Ciências Contábeis da UNEMAT - campus de Tangará da Serra no mercado de trabalho

Luciene Pereira Viana, Laércio Juarez Melz, Josiane Silva Costa dos Santos, Eugênio Carlos Stieler

questionário contendo vinte e sete perguntas, onde os egressos responderam quanto a sua profissão, remuneração entre outros para a realização do trabalho.

Foram encaminhados 180 questionários no período de 23 de julho até 31de agosto, através de correio eletrônico e das redes sociais faceboock, Messenger (msn), o questionário foi disponibilizado através de um site especifico do Google Docs. O site foi escolhido por ser grátis e importar os arquivos e converter automaticamente para planilha. Também tem a capacidade de exportar os arquivos para os formatos convencionais. As respostas eram encaminhadas automaticamente para uma planilha do EXCEL, pelo fato de não ter dados suficientes para encontrá-los e por indisponibilidade de tempo para a realização da pesquisa, obteve-se um retorno de 74 questionários. Verificou-se que no ano de 2005 somente 1 egresso respondeu o questionário, no ano de 2006 ninguém respondeu, já no ano de 20078 dos concluintes responderam ao questionário, no ano de 2008 4, no ano de 200915 egressos responderam, por ser mais recente 20 dos concluinte responderam o questionário no ano de 2012, e por fim no ano de 2011 foi o onde houve mais colaboração dos egressos totalizando 26 respostas.

Desta maneira tornou mais prático à elaboração das tabelas, com a finalidade de demonstrar com mais clareza os resultados obtidos a partir destes resultados verificou-se que a maioria dos egressos entrevistados que responderam ao questionário são do sexo feminino chegando a $55,41 \%$ e o sexo masculino com $44,59 \%$, do total da pesquisa.

\section{RESULTADOS}

O trabalho teve como fonte de estudos os egressos do curso de Ciências Contábeis da UNEMAT Campus de Tangará da Serra, que obtiveram o titulo de bacharel em contabilidade nos anos de 2005 a 2011. A demonstração e apresentação dos dados obtidos com a pesquisa foi por meio de tabelas com os tópicos e seus percentuais. Os resultados foram estruturados quanto à formação, registro no CRC, atuação profissional e perspectivas da profissão.

\subsection{Quanto à formação}

Atualmente, a profissão contábil passa por um processo de transição da fase técnica para a fase da informação, onde o profissional se torna um agente de mudanças que deverá mostrar suas diversas habilidades. A profissão contábil é uma das áreas de trabalho que apresenta maior crescimento e que mais proporciona oportunidades de trabalho como: 
contador de empresa pública e privada, auditor, professor, analista financeiro, perito, controller, consultor ou pesquisador contábil (MARION, 2005).

No questionário aplicado aos egressos do curso de Ciências Contábeis da UNEMAT Campus de Tangará da Serra no período de 2005 a 2011. Os egressos foram questionados sobre os motivos que levaram a escolha do curso de graduação foi aberta para mais de uma resposta. Conforme a tabela 1 verificou-se que mercado de trabalho foi a que mais destacou dentre as opções com 37,84\%, com 32,44\% optaram pela graduação em Ciências Contábeis por estar atuando na área, 9,46\% escolheram vocação como opção e 6,76\% escolheram o curso por interferência de familiares.

Tabela 1: Quanto aos motivos que os levaram a escolher o curso de graduação, em \%.

\begin{tabular}{cccccccc}
\hline Resposta & $\mathbf{2 0 0 5}$ & $\mathbf{2 0 0 7}$ & $\mathbf{2 0 0 8}$ & $\mathbf{2 0 0 9}$ & $\mathbf{2 0 1 0}$ & $\mathbf{2 0 1 1}$ & $\begin{array}{c}\text { Total } \\
\text { Geral }\end{array}$ \\
\hline Interferência de familiares & $10,00 \%$ & $0,00 \%$ & $0,00 \%$ & $6,67 \%$ & $0,00 \%$ & $11,54 \%$ & $6,76 \%$ \\
\hline $\begin{array}{c}\text { Interferência de familiares, } \\
\text { Mercado de trabalho }\end{array}$ & $0,00 \%$ & $0,00 \%$ & $0,00 \%$ & $0,00 \%$ & $5,00 \%$ & $0,00 \%$ & $2,70 \%$ \\
\hline Mercado de trabalho & $0,00 \%$ & $12,50 \%$ & $50,00 \%$ & $53,33 \%$ & $40,00 \%$ & $34,62 \%$ & $37,84 \%$ \\
\hline Trabalhava na área & $0,00 \%$ & $37,50 \%$ & $25,00 \%$ & $0,00 \%$ & $25,00 \%$ & $11,54 \%$ & $32,44 \%$ \\
\hline $\begin{array}{c}\text { Trabalhava na área, Mercado de } \\
\text { trabalho }\end{array}$ & $0,00 \%$ & $0,00 \%$ & $0,00 \%$ & $0,00 \%$ & $5,00 \%$ & $0,00 \%$ & $2,70 \%$ \\
\hline Vocação & $0,00 \%$ & $12,50 \%$ & $0,00 \%$ & $20,00 \%$ & $5,00 \%$ & $7,69 \%$ & $9,46 \%$ \\
\hline Vocação, Mercado de trabalho & $0,00 \%$ & $0,00 \%$ & $0,00 \%$ & $0,00 \%$ & $0,00 \%$ & $3,85 \%$ & $1,35 \%$ \\
\hline Vocação, Trabalhava na área & $0,00 \%$ & $12,50 \%$ & $0,00 \%$ & $0,00 \%$ & $0,00 \%$ & $7,69 \%$ & $5,40 \%$ \\
\hline Não Respondeu & $0,00 \%$ & $0,00 \%$ & $0,00 \%$ & $6,67 \%$ & $0,00 \%$ & $0,00 \%$ & $1,35 \%$ \\
\hline Total Geral & $\mathbf{0 , 0 0 \%}$ & $\mathbf{1 0 0 , 0 0 \%}$ & $\mathbf{1 0 0 , 0 0 \%}$ & $\mathbf{1 0 0 , 0 0 \%}$ & $\mathbf{1 0 0 , 0 0 \%}$ & $\mathbf{1 0 0 , 0 0 \%}$ & $\mathbf{1 0 0 , 0 0 \%}$ \\
\hline
\end{tabular}

Os egressos responderam quanto à segurança para atuar na área de formação, de acordo com tabela 2 verificou- se que $12,16 \%$ dos entrevistados sentem-se inseguros devido à falta de experiência e oportunidade de ingressarem na área, 67,57\% consideram-se seguros e apenas $20,27 \%$ dos egressos entrevistados estão totalmente confiantes, pois já atuavam na área contábil antes de iniciar o curso.

Tabela 2: Quanto à segurança para atuar na área, em \%.

\begin{tabular}{cccccccc}
\hline Resposta & $\mathbf{2 0 0 5}$ & $\mathbf{2 0 0 7}$ & $\mathbf{2 0 0 8}$ & $\mathbf{2 0 0 9}$ & $\mathbf{2 0 1 0}$ & $\mathbf{2 0 1 1}$ & $\begin{array}{c}\text { Total } \\
\text { Geral }\end{array}$ \\
\hline Inseguro & $0,00 \%$ & $0,00 \%$ & $25,00 \%$ & $6,67 \%$ & $15,00 \%$ & $15,38 \%$ & $12,16 \%$ \\
\hline $\begin{array}{c}\text { Seguro para atuar } \\
\text { sozinho }\end{array}$ & $100,00 \%$ & $50,00 \%$ & $50,00 \%$ & $0,00 \%$ & $15,00 \%$ & $19,23 \%$ & $20,27 \%$ \\
\hline $\begin{array}{c}\text { Seguro para atuar } \\
\text { supervisionado }\end{array}$ & $0,00 \%$ & $50,00 \%$ & $25,00 \%$ & $93,33 \%$ & $70,00 \%$ & $65,38 \%$ & $67,57 \%$ \\
\hline Total Geral & $\mathbf{1 0 0 , 0 0 \%}$ & $\mathbf{1 0 0 , 0 0 \%}$ & $\mathbf{1 0 0 , 0 0 \%}$ & $\mathbf{1 0 0 , 0 0 \%}$ & $\mathbf{1 0 0 , 0 0 \%}$ & $\mathbf{1 0 0 , 0 0 \%}$ & $\mathbf{1 0 0 , 0 0 \%}$ \\
\hline
\end{tabular}


O mercado exige dos profissionais contábeis uma necessidade de maior qualificação e constante atualização aprofundando seus conhecimentos a fim de atender a demanda das informações contábeis (DEITOS, 2008).

Analisando a tabela 3, verifica-se que 51,35\% dos egressos entrevistados continuaram investindo na obtenção de aprimorar o conhecimento intelectual e profissional através da pósgraduação, $14,86 \%$ buscaram na pós-graduação um aprendizado para seguir carreira acadêmica ou de pesquisa, 10,81\% investiram na pós-graduação por exigência do mercado de trabalho, $2,70 \%$ por opção financeira imediata, e $20,27 \%$ não responderam a questão. "O mundo está altamente competitivo, onde a graduação é o primeiro passo para a longa jornada do desejo de alcançar o sucesso, então se faz necessária a qualificação profissional, somente assim os resultados positivos podem acontecer" (Soczek, 2010, p. 47).

Tabela 3: Quanto à opção de pós-graduação, em \%:

\begin{tabular}{cccccccc}
\hline Resposta & $\mathbf{2 0 0 5}$ & $\mathbf{2 0 0 7}$ & $\mathbf{2 0 0 8}$ & $\mathbf{2 0 0 9}$ & $\mathbf{2 0 1 0}$ & $\mathbf{2 0 1 1}$ & $\begin{array}{c}\text { Total } \\
\text { Geral }\end{array}$ \\
\hline $\begin{array}{c}\text { Aprimorar os } \\
\text { conhecimentos }\end{array}$ & $0,00 \%$ & $50,00 \%$ & $50,00 \%$ & $46,67 \%$ & $55,00 \%$ & $53,85 \%$ & $51,35 \%$ \\
\hline $\begin{array}{c}\text { Exigência do mercado } \\
\text { de trabalho }\end{array}$ & $0,00 \%$ & $25,00 \%$ & $0,00 \%$ & $6,67 \%$ & $10,00 \%$ & $11,54 \%$ & $10,81 \%$ \\
\hline $\begin{array}{c}\text { Opção financeira } \\
\text { imediata }\end{array}$ & $0,00 \%$ & $0,00 \%$ & $0,00 \%$ & $0,00 \%$ & $10,00 \%$ & $0,00 \%$ & $2,70 \%$ \\
\hline Outros & $0,00 \%$ & $25,00 \%$ & $0,00 \%$ & $13,33 \%$ & $25,00 \%$ & $23,08 \%$ & $20,27 \%$ \\
\hline $\begin{array}{c}\text { Seguir carreira } \\
\text { acadêmica ou pesquisa }\end{array}$ & $100,00 \%$ & $0,00 \%$ & $50,00 \%$ & $33,33 \%$ & $0,00 \%$ & $11,54 \%$ & $14,86 \%$ \\
\hline Total Geral & $\mathbf{1 0 0 , 0 0 \%}$ & $\mathbf{1 0 0 , 0 0 \%}$ & $\mathbf{1 0 0 , 0 0 \%}$ & $\mathbf{1 0 0 , 0 0 \%}$ & $\mathbf{1 0 0 , 0 0 \%}$ & $\mathbf{1 0 0 , 0 0 \%}$ & $\mathbf{1 0 0 , 0 0 \%}$ \\
\hline
\end{tabular}

Com os resultados obtidos através da pesquisa realizada com os egressos do curso de Ciências Contábeis da UNEMAT Tangara da Serra, percebeu-se que 87,84\% dos concluintes não possuem graduação adicional e apenas $12,16 \%$ dos concluintes do curso de Ciências Contábeis buscaram outra formação adicional. Em relação à formação de pós-graduação $56,76 \%$ dos egressos entrevistados fizeram uma pós-graduação e estão em busca de mais conhecimento para se tornar um profissional qualificado e suprir as necessidades do mercado de trabalho e os outros 43,24\% não buscaram uma especialização fora do nível superior.

Através da pesquisa realizada com os egressos do curso de Ciências Contábeis os entrevistados responderam quanto à preparação para ingressar no mercado de trabalho de acordo com a tabela 4 nota-se que 45,95\% dos egressos estavam razoavelmente preparados para ingressar no mercado de trabalho, $32,43 \%$ se sentiam pouco preparados, $5,41 \%$ não se sentiam preparados para mercado de trabalho e apenas $16,22 \%$ dos entrevistados sentiam muito bem preparados para ingressar no mercado de trabalho. 
Atuação do egresso do curso de Ciências Contábeis da UNEMAT - campus de Tangará da Serra no mercado de trabalho

Luciene Pereira Viana, Laércio Juarez Melz, Josiane Silva Costa dos Santos, Eugênio Carlos Stieler

Tabela 4: Quanto ao mercado de trabalho estava preparado quando se formou, em \%:

\begin{tabular}{cccccccc}
\hline Resposta & $\mathbf{2 0 0 5}$ & $\mathbf{2 0 0 7}$ & $\mathbf{2 0 0 8}$ & $\mathbf{2 0 0 9}$ & $\mathbf{2 0 1 0}$ & $\mathbf{2 0 1 1}$ & Total Geral \\
\hline Muito & $100,00 \%$ & $25,00 \%$ & $25,00 \%$ & $13,33 \%$ & $25,00 \%$ & $3,85 \%$ & $16,22 \%$ \\
\hline Nada & $0,00 \%$ & $12,50 \%$ & $0,00 \%$ & $0,00 \%$ & $5,00 \%$ & $7,69 \%$ & $5,41 \%$ \\
\hline Pouco & $0,00 \%$ & $12,50 \%$ & $25,00 \%$ & $46,67 \%$ & $20,00 \%$ & $42,31 \%$ & $32,43 \%$ \\
\hline Razoavelmente & $0,00 \%$ & $50,00 \%$ & $50,00 \%$ & $40,00 \%$ & $50,00 \%$ & $46,15 \%$ & $45,95 \%$ \\
\hline Total Geral & $\mathbf{1 0 0 , 0 0 \%}$ & $\mathbf{1 0 0 , 0 0 \%}$ & $\mathbf{1 0 0 , 0 0 \%}$ & $\mathbf{1 0 0 , 0 0 \%}$ & $\mathbf{1 0 0 , 0 0 \%}$ & $\mathbf{1 0 0 , 0 0 \%}$ & $\mathbf{1 0 0 , 0 0 \%}$ \\
\hline
\end{tabular}

\subsection{Registro no Conselho Regional de Contabilidade}

O Exame de Suficiência foi instituído pela Lei n ${ }^{\circ}$ 12.249/2010, que alterou o artigo 12 do Decreto-Lei $n^{\circ}$ 9.295/46. De acordo com a nova redação, esse artigo estabelece que os profissionais contábeis somente poderão exercer a profissão mediante os seguintes requisitos: conclusão do curso de Bacharelado em Ciências Contábeis ou de Técnico em Contabilidade, aprovação em Exame de Suficiência e registro no Conselho Regional de Contabilidade (CRC). Art. 18. O profissional apto para requerer o registro e aquele com registro baixado poderá efetuar ou restabelecer seu registro sem se submeter ao Exame de que trata esta Resolução, até a data limite de 29 de outubro de 2010 (CARNEIRO, 2010).

Os egressos responderam quanto o Registro no Conselho Regional de Contabilidade, como pode-se verificar na tabela 5 que 47,30\% do egressos possuem o Registro do CRC e deste percentual 28,07\% não submeteram ao Exame de Suficiência e 19,23\% dos graduados entrevistados foram aprovados no Exame de Suficiência e os outros 52,70\% não possuem o registro do CRC.

Tabela 5: Possui registo no Conselho Regional de Contabilidade, em \%.

\begin{tabular}{cccccccc}
\hline Resposta & $\mathbf{2 0 0 5}$ & $\mathbf{2 0 0 7}$ & $\mathbf{2 0 0 8}$ & $\mathbf{2 0 0 9}$ & $\mathbf{2 0 1 0}$ & $\mathbf{2 0 1 1}$ & Total Geral \\
\hline Não & $100,00 \%$ & $37,50 \%$ & $25,00 \%$ & $20,00 \%$ & $50,00 \%$ & $80,77 \%$ & $52,70 \%$ \\
\hline Sim & $0,00 \%$ & $62,50 \%$ & $75,00 \%$ & $80,00 \%$ & $50,00 \%$ & $19,23 \%$ & $47,30 \%$ \\
\hline Total Geral & $\mathbf{1 0 0 , 0 0 \%}$ & $\mathbf{1 0 0 , 0 0 \%}$ & $\mathbf{1 0 0 , 0 0 \%}$ & $\mathbf{1 0 0 , 0 0 \%}$ & $\mathbf{1 0 0 , 0 0 \%}$ & $\mathbf{1 0 0 , 0 0 \%}$ & $\mathbf{1 0 0 , 0 0 \%}$ \\
\hline
\end{tabular}

\subsection{Atuação profissional}

Quanto os ingressantes no curso de Ciências Contábeis conforme a tabela 6 verifica-se que $71,62 \%$ não atuavam na área contábil ao iniciar o curso. Porém, verificou-se na entrevista que a falta de e experiência e oportunidade é o que impediam de inserir no mercado de trabalho, e somente $27,03 \%$ atuavam na área contábil antes de iniciar o curso.

Tabela 6: Quanto à atuação na área da contabilidade antes de iniciar o curso, em \%.

\begin{tabular}{cccccccc}
\hline Resposta & $\mathbf{2 0 0 5}$ & $\mathbf{2 0 0 7}$ & $\mathbf{2 0 0 8}$ & $\mathbf{2 0 0 9}$ & $\mathbf{2 0 1 0}$ & $\mathbf{2 0 1 1}$ & Total Geral \\
\hline Não & $100,00 \%$ & $50,00 \%$ & $50,00 \%$ & $80,00 \%$ & $70,00 \%$ & $76,92 \%$ & $71,62 \%$ \\
\hline Sim & $0,00 \%$ & $50,00 \%$ & $25,00 \%$ & $20,00 \%$ & $30,00 \%$ & $23,08 \%$ & $27,03 \%$ \\
\hline Não Respondeu & $0,00 \%$ & $0,00 \%$ & $25,00 \%$ & $0,00 \%$ & $0,00 \%$ & $0,00 \%$ & $1,35 \%$ \\
\hline Total Geral & $\mathbf{1 0 0 , 0 0 \%}$ & $\mathbf{1 0 0 , 0 0 \%}$ & $\mathbf{1 0 0 , 0 0 \%}$ & $\mathbf{1 0 0 , 0 0 \%}$ & $\mathbf{1 0 0 , 0 0 \%}$ & $\mathbf{1 0 0 , 0 0 \%}$ & $\mathbf{1 0 0 , 0 0 \%}$ \\
\hline
\end{tabular}


Esta análise se comparada com a anterior é bem expressiva, pois, verifica-se que a atuação na área contábil aumentou consideravelmente como pode-se ver na tabela 7 que 63,51\% dos concluintes do curso de Ciências Contábeis estão atuando na sua área de formação, isto demonstra que a graduação melhorou a posição dos egressos no mercado de trabalho e 36,49\% não atuam em sua área de formação devido à falta de experiência e oportunidade para adquiri-la.

Tabela 7: Atua profissionalmente na sua área de formação, em \%.

\begin{tabular}{cccccccc}
\hline Reposta & $\mathbf{2 0 0 5}$ & $\mathbf{2 0 0 7}$ & $\mathbf{2 0 0 8}$ & $\mathbf{2 0 0 9}$ & $\mathbf{2 0 1 0}$ & $\mathbf{2 0 1 1}$ & Total Geral \\
\hline Não & $0,00 \%$ & $25,00 \%$ & $50,00 \%$ & $33,33 \%$ & $40,00 \%$ & $38,46 \%$ & $36,49 \%$ \\
\hline Sim & $100,00 \%$ & $75,00 \%$ & $50,00 \%$ & $66,67 \%$ & $60,00 \%$ & $61,54 \%$ & $63,51 \%$ \\
\hline Total Geral & $\mathbf{1 0 0 , 0 0 \%}$ & $\mathbf{1 0 0 , 0 0 \%}$ & $\mathbf{1 0 0 , 0 0 \%}$ & $\mathbf{1 0 0 , 0 0 \%}$ & $\mathbf{1 0 0 , 0 0 \%}$ & $\mathbf{1 0 0 , 0 0 \%}$ & $\mathbf{1 0 0 , 0 0 \%}$ \\
\hline
\end{tabular}

Os egressos entrevistados do curso de Ciências Contábeis da UNEMAT Campus de Tangará da Serra entre o período de 2005 a 2011 responderam quanto às dificuldades na contratação e dificuldades em acompanhar as inovações tecnológicas conforme a tabela 8 nota-se que $43,66 \%$ dos egressos responderam que não enfrentaram dificuldades na contratação ou execução da profissão no mercado trabalho e não tiveram dificuldades em acompanhar as inovações tecnológicas pelo fato de estarem atuando na área de formação, com o percentual de $21,13 \%$ responderam sim, que encontraram dificuldades tanto na contratação quanto em acompanhar transformações e inovações na sua área de formação.

Tabela 8: Relação entre dificuldade em acompanhar tecnologias e dificuldade na contratação, em \% do total de respostas.

\begin{tabular}{c|c|c|c}
\hline \multirow{2}{*}{$\begin{array}{c}\text { total de respostas. } \\
\begin{array}{c}\text { Enfrentou dificuldades na contratação e / ou execução } \\
\text { da profissão no mercado de trabalho? }\end{array}\end{array}$} & $\begin{array}{c}\text { Teve dificuldade em acompanhar as } \\
\text { transformações e / ou inovações tecnológicas } \\
\text { da sua área de formação? }\end{array}$ \\
\cline { 2 - 4 } & Não & Sim & Total Geral \\
\hline Não & $43,66 \%$ & $19,72 \%$ & $63,38 \%$ \\
\hline Sim & $11,27 \%$ & $21,13 \%$ & $32,39 \%$ \\
\hline Não Respondeu & $2,82 \%$ & $1,41 \%$ & $4,23 \%$ \\
\hline Total Geral & $57,75 \%$ & $42,25 \%$ & $100,00 \%$ \\
\hline
\end{tabular}

No questionário aplicado esta questão sobre as dificuldades encontradas para a contratação na área contábil foi aberta para mais de uma resposta. Conforme a tabela 9 a resposta que mais destacou foi à falta de experiência com 36,27\%, destacam-se também com $17,22 \%$ falta de experiência e forte concorrência para obter emprego, 15,87\% responderam que a dificuldade encontrada foi a concorrência, $14,42 \%$ responderam que além da falta de 
experiência o domínio de uma língua estrangeria dificultou a inserção no mercado de trabalho e $16,22 \%$ julgaram ter outros motivos, mas não mencionaram quais.

Tabela 9: Quanto às dificuldades encontradas, em \%.

\begin{tabular}{cccccccc}
\hline Resposta & $\mathbf{2 0 0 5}$ & $\mathbf{2 0 0 7}$ & $\mathbf{2 0 0 8}$ & $\mathbf{2 0 0 9}$ & $\mathbf{2 0 1 0}$ & $\mathbf{2 0 1 1}$ & Total Geral \\
\hline Falta de experiência & $0,00 \%$ & $12,50 \%$ & $0,00 \%$ & $26,67 \%$ & $25,00 \%$ & $26,92 \%$ & $36,27 \%$ \\
\hline $\begin{array}{c}\text { Falta de experiência, } \\
\text { Falta de domínio de } \\
\text { uma língua estrangeira }\end{array}$ & $0,00 \%$ & $12,50 \%$ & $0,00 \%$ & $0,00 \%$ & $0,00 \%$ & $0,00 \%$ & $14,42 \%$ \\
\hline $\begin{array}{c}\text { Falta de experiência, } \\
\text { Forte concorrência } \\
\text { para obter emprego }\end{array}$ & $0,00 \%$ & $0,00 \%$ & $0,00 \%$ & $6,67 \%$ & $0,00 \%$ & $7,69 \%$ & $17,22 \%$ \\
\hline $\begin{array}{c}\text { Forte concorrência } \\
\text { para obter emprego }\end{array}$ & $100,00 \%$ & $0,00 \%$ & $0,00 \%$ & $0,00 \%$ & $0,00 \%$ & $3,85 \%$ & $15,87 \%$ \\
\hline Outra & $0,00 \%$ & $12,50 \%$ & $25,00 \%$ & $6,67 \%$ & $30,00 \%$ & $11,54 \%$ & $16,22 \%$ \\
\hline Total Geral & $\mathbf{1 0 0 , 0 0 \%}$ & $\mathbf{1 0 0 , 0 0 \%}$ & $\mathbf{1 0 0 , 0 0 \%}$ & $\mathbf{1 0 0 , 0 0 \%}$ & $\mathbf{1 0 0 , 0 0 \%}$ & $\mathbf{1 0 0 , 0 0 \%}$ & $\mathbf{1 0 0 , 0 0 \%}$ \\
\hline
\end{tabular}

No setor de atuação duas das opções disponíveis no questionário tiveram mais destaques. Como é possível observar na tabela 10 o primeiro setor com mais destaque foi o de serviços alcançou um percentual de 33,78\% das respostas e em segundo o setor empresarial com um percentual de 32,43\% em seguido o setor agropecuário com $6,76 \%$, o setor da educação e o industrial com 5,41\% cada, e outros setores que não foram citados no questionário com 14,66\% e 1,35\% dos entrevistados não responderam a pergunta.

Tabela 10: Quanto o setor de atuação, em \%.

\begin{tabular}{cccccccc}
\hline Resposta & $\mathbf{2 0 0 5}$ & $\mathbf{2 0 0 7}$ & $\mathbf{2 0 0 8}$ & $\mathbf{2 0 0 9}$ & $\mathbf{2 0 1 0}$ & $\mathbf{2 0 1 1}$ & Total Geral \\
\hline Agropecuário & $0,00 \%$ & $12,50 \%$ & $0,00 \%$ & $6,67 \%$ & $0,00 \%$ & $11,54 \%$ & $6,76 \%$ \\
\hline Educação & $0,00 \%$ & $0,00 \%$ & $0,00 \%$ & $13,33 \%$ & $0,00 \%$ & $7,69 \%$ & $5,41 \%$ \\
\hline Empresarial & $100,00 \%$ & $12,50 \%$ & $50,00 \%$ & $40,00 \%$ & $30,00 \%$ & $30,77 \%$ & $32,43 \%$ \\
\hline Industrial & $0,00 \%$ & $12,50 \%$ & $0,00 \%$ & $13,33 \%$ & $0,00 \%$ & $3,85 \%$ & $5,41 \%$ \\
\hline Outros & $0,00 \%$ & $0,00 \%$ & $25,00 \%$ & $13,33 \%$ & $25,00 \%$ & $11,54 \%$ & $14,86 \%$ \\
\hline Serviços & $0,00 \%$ & $62,50 \%$ & $25,00 \%$ & $13,33 \%$ & $45,00 \%$ & $30,77 \%$ & $33,78 \%$ \\
\hline Não Respondeu & $0,00 \%$ & $0,00 \%$ & $0,00 \%$ & $0,00 \%$ & $0,00 \%$ & $3,85 \%$ & $1,35 \%$ \\
\hline Total Geral & $\mathbf{1 0 0 , 0 0 \%}$ & $\mathbf{1 0 0 , 0 0 \%}$ & $\mathbf{1 0 0 , 0 0 \%}$ & $\mathbf{1 0 0 , 0 0 \%}$ & $\mathbf{1 0 0 , 0 0 \%}$ & $\mathbf{1 0 0 , 0 0 \%}$ & $\mathbf{1 0 0 , 0 0 \%}$ \\
\hline
\end{tabular}

Houve números expressivos perante as instituições privadas como a tabela 11 nos mostra que $67,57 \%$, já a pública obteve $10,81 \%$, a própria com $8,11 \%$, aos que não atuam na área de formação teve um percentual de $9,46 \%$ e com $2,70 \%$ dos entrevistados não responderam a questão.

Como pode-se perceber e bem baixo o percentual de concluintes que não atuam em uma das diversas áreas que a contabilidade proporciona.

Tabela 11: Quanto ao tipo de instituição que trabalha, em \%.

\begin{tabular}{llllllllll}
\hline Resposta & 2005 & 2007 & 2008 & 2009 & 2010 & 2011 & $\begin{array}{c}\text { Total } \\
\text { Geral }\end{array}$ \\
\hline
\end{tabular}


Atuação do egresso do curso de Ciências Contábeis da UNEMAT - campus de Tangará da Serra no mercado de trabalho

Luciene Pereira Viana, Laércio Juarez Melz, Josiane Silva Costa dos Santos, Eugênio Carlos Stieler

\begin{tabular}{|c|c|c|c|c|c|c|c|}
\hline $\begin{array}{l}\text { A pergunta não se aplica a minha } \\
\text { situação atual }\end{array}$ & $0,00 \%$ & $12,50 \%$ & $0,00 \%$ & $6,67 \%$ & $15,00 \%$ & $7,69 \%$ & $9,46 \%$ \\
\hline Autônoma & $0,00 \%$ & $0,00 \%$ & $25,00 \%$ & $0,00 \%$ & $0,00 \%$ & $0,00 \%$ & $1,35 \%$ \\
\hline Privada & $\begin{array}{c}100,00 \\
\%\end{array}$ & $\begin{array}{c}75,00 \\
\%\end{array}$ & $\begin{array}{c}25,00 \\
\%\end{array}$ & $\begin{array}{c}66,67 \\
\%\end{array}$ & $\begin{array}{c}60,00 \\
\%\end{array}$ & $\begin{array}{c}76,92 \\
\%\end{array}$ & $\begin{array}{c}67,57 \\
\%\end{array}$ \\
\hline Própria & $0,00 \%$ & $12,50 \%$ & $25,00 \%$ & $13,33 \%$ & $10,00 \%$ & $0,00 \%$ & $8,11 \%$ \\
\hline Pública & $0,00 \%$ & $0,00 \%$ & $25,00 \%$ & $13,33 \%$ & $10,00 \%$ & $11,54 \%$ & $10,81 \%$ \\
\hline Não Respondeu & $0,00 \%$ & $0,00 \%$ & $0,00 \%$ & $0,00 \%$ & $5,00 \%$ & $3,85 \%$ & $2,70 \%$ \\
\hline Total Geral & $\begin{array}{c}100,00 \\
\%\end{array}$ & $\begin{array}{c}100,00 \\
\%\end{array}$ & $\begin{array}{c}100,00 \\
\%\end{array}$ & $\begin{array}{c}100,00 \\
\%\end{array}$ & $\begin{array}{c}100,00 \\
\%\end{array}$ & $\begin{array}{c}100,00 \\
\%\end{array}$ & $\begin{array}{c}100,00 \\
\%\end{array}$ \\
\hline
\end{tabular}

Considerando as ramificações da contabilidade infelizmente a classe dos contadores deixa a desejar quanto à remuneração. Como pode analisar na tabela 12 que 4,05\% dos egressos entrevistados tem renda mensal acima de 6.000 reais, $10,81 \%$ tem sua renda mensal de $4.001,00$ a 6.000 reais, $35,14 \%$ de $2.001,00$ a 4.000 reais mensais e a grande maioria dos entrevistados respondeu que sua renda varia entre 1.000,00 a 2.000,00. Infelizmente um dos motivos para não seguir carreira em uma das varias áreas oferecidas pela contabilidade e devido ao baixo salario oferecido ao profissional.

Tabela 12: Quanto à remuneração, em \%.

\begin{tabular}{cccccccc}
\hline Resposta & $\mathbf{2 0 0 5}$ & $\mathbf{2 0 0 7}$ & $\mathbf{2 0 0 8}$ & $\mathbf{2 0 0 9}$ & $\mathbf{2 0 1 0}$ & $\mathbf{2 0 1 1}$ & Total Geral \\
\hline $\mathrm{R} \$ 1.000,00$ á R \$ 2.000,000 & $100,00 \%$ & $37,50 \%$ & $25,00 \%$ & $60,00 \%$ & $30,00 \%$ & $57,69 \%$ & $47,30 \%$ \\
\hline $\mathrm{R} \$ 2.001,00$ á R \$ 4.000,00 & $0,00 \%$ & $25,00 \%$ & $50,00 \%$ & $26,67 \%$ & $45,00 \%$ & $34,62 \%$ & $35,14 \%$ \\
\hline $\mathrm{R} \$ 4.001,00$ á R \$ 6.000,00 & $0,00 \%$ & $12,50 \%$ & $25,00 \%$ & $6,67 \%$ & $15,00 \%$ & $7,69 \%$ & $10,81 \%$ \\
\hline Acima de R\$ 6.000,00 & $0,00 \%$ & $25,00 \%$ & $0,00 \%$ & $0,00 \%$ & $5,00 \%$ & $0,00 \%$ & $4,05 \%$ \\
\hline Não Respondeu & $0,00 \%$ & $0,00 \%$ & $0,00 \%$ & $6,67 \%$ & $5,00 \%$ & $0,00 \%$ & $2,70 \%$ \\
\hline Total Geral & $\mathbf{1 0 0 , 0 0 \%}$ & $\mathbf{1 0 0 , 0 0 \%}$ & $\mathbf{1 0 0 , 0 0 \%}$ & $\mathbf{1 0 0 , 0 0 \%}$ & $\mathbf{1 0 0 , 0 0 \%}$ & $\mathbf{1 0 0 , 0 0 \%}$ & $\mathbf{1 0 0 , 0 0 \%}$ \\
\hline
\end{tabular}

Na tabela 13 é possível notar que após o termino do curso os concluintes não obtiveram um aumento salarial significativo, dos entrevistados 48,65\% tiveram aumento enquanto que 47,30\% não, essa desvalorização é desanimadora. Conforme Soczek (2010, p. 48) "a classe contábil é desunida, onde a maioria não segue a tabela de honorários propostos pelo Conselho Federal de Contabilidade (CFC), assim cria-se um ciclo que gera alta competitividade, baixa remuneração para os colaboradores e descontentamento da profissão", e $4.05 \%$ não responderam a questão.

Tabela 13: Quanto à faixa salarial após o termino do curso, em \%.

\begin{tabular}{cccccccc}
\hline Resposta & $\mathbf{2 0 0 5}$ & $\mathbf{2 0 0 7}$ & $\mathbf{2 0 0 8}$ & $\mathbf{2 0 0 9}$ & $\mathbf{2 0 1 0}$ & $\mathbf{2 0 1 1}$ & \multicolumn{2}{c}{ Total Geral } \\
\hline Não & $100,00 \%$ & $50,00 \%$ & $0,00 \%$ & $60,00 \%$ & $45,00 \%$ & $46,15 \%$ & $47,30 \%$ \\
\hline Sim & $0,00 \%$ & $50,00 \%$ & $75,00 \%$ & $40,00 \%$ & $50,00 \%$ & $50,00 \%$ & $48,65 \%$ \\
\hline Não Respondeu & $0,00 \%$ & $0,00 \%$ & $25,00 \%$ & $0,00 \%$ & $5,00 \%$ & $3,85 \%$ & $4,05 \%$ \\
\hline Total Geral & $\mathbf{1 0 0 , 0 0 \%}$ & $\mathbf{1 0 0 , 0 0 \%}$ & $\mathbf{1 0 0 , 0 0 \%}$ & $\mathbf{1 0 0 , 0 0 \%}$ & $\mathbf{1 0 0 , 0 0 \%}$ & $\mathbf{1 0 0 , 0 0 \%}$ & $\mathbf{1 0 0 , 0 0 \%}$ \\
\hline
\end{tabular}




\subsection{Perspectiva profissional na área}

Alcazar (2009) descreve o mercado de trabalho para o contador com boas perspectivas e muitas oportunidades de emprego devido às várias mudanças ocorridas no cenário da contabilidade e pelo momento oportuno que a profissão atravessa no país. O profissional tem que ser versátil, dinâmico, atualizado, disciplinado e organizado para que esse espaço se desenvolva aumentando assim, sua oportunidade de alcançar uma carreira de sucesso.

Os egressos responderam quanto à perspectiva profissional na área, pode-se verificar na tabela 14 que a maioria tem boas perspectivas em relação ao curso com percentual de $44,59 \%$, com um percentual de $22,97 \%$ dos entrevistados disseram que as perspectivas são ótimas, com 28,38\% acham razoável e 4,05\% desanimador.

Tabela 14 Quanto á perspectiva profissional na área, em \%.

\begin{tabular}{cccccccc}
\hline Resposta & $\mathbf{2 0 0 5}$ & $\mathbf{2 0 0 7}$ & $\mathbf{2 0 0 8}$ & $\mathbf{2 0 0 9}$ & $\mathbf{2 0 1 0}$ & $\mathbf{2 0 1 1}$ & Total Geral \\
\hline Boa & $0,00 \%$ & $25,00 \%$ & $75,00 \%$ & $46,67 \%$ & $40,00 \%$ & $50,00 \%$ & $44,59 \%$ \\
\hline Desanimadora & $0,00 \%$ & $0,00 \%$ & $0,00 \%$ & $0,00 \%$ & $5,00 \%$ & $7,69 \%$ & $4,05 \%$ \\
\hline Ótima & $100,00 \%$ & $50,00 \%$ & $0,00 \%$ & $20,00 \%$ & $25,00 \%$ & $15,38 \%$ & $22,97 \%$ \\
\hline Razoável & $0,00 \%$ & $25,00 \%$ & $25,00 \%$ & $33,33 \%$ & $30,00 \%$ & $26,92 \%$ & $28,38 \%$ \\
\hline Total Geral & $\mathbf{1 0 0 , 0 0 \%}$ & $\mathbf{1 0 0 , 0 0 \%}$ & $\mathbf{1 0 0 , 0 0 \%}$ & $\mathbf{1 0 0 , 0 0 \%}$ & $\mathbf{1 0 0 , 0 0 \%}$ & $\mathbf{1 0 0 , 0 0 \%}$ & $\mathbf{1 0 0 , 0 0 \%}$ \\
\hline
\end{tabular}

\section{CONCLUSÃO}

O estudo apresentado teve como objetivo analisar as inúmeras áreas de atuação do curso de ciências contábeis, e estudar quais destas áreas os formandos da UNEMAT Campus de Tangará da Serra está ingressado. A partir dos resultados obtidos conclui-se que o objetivo dessa pesquisa foi alcançado, pois $63,51 \%$ dos egressos entrevistados que responderam o questionário estão atuando na sua área de formação, tanto em empresas privada, publica, e em diversos setores devido à ramificação que a área contábil oferece tais como, agropecuário, educação, empresarial, industrial e prestação de serviços entre outros que não foram citados no questionário.

Os egressos responderam quanto à perspectiva profissional na área, foi possível verificar que a maioria tem boas perspectivas em relação ao curso com percentual de 44,59\%, com um percentual de $22,97 \%$ dos entrevistados disseram que as perspectivas são ótimas, com $28,38 \%$ acham razoável e 4,05\% desanimador. Um dado relevante que observa na pesquisa é que $51,35 \%$ dos egressos entrevistados continuaram investindo na obtenção de aprimorar o conhecimento intelectual e profissional através da pós-graduação, 14,86\% 
buscou na pós-graduação um aprendizado para seguir carreira acadêmica ou de pesquisa, $10,81 \%$ investiram na pós-graduação por exigência do mercado de trabalho, $2,70 \%$ por opção financeira imediata.

Quanto à condição profissional dos egressos antes de iniciar o curso de Ciências Contábeis verificou-se que 71,62\% não atuavam na área contábil, e somente 27,03\% atuavam na área contábil antes de iniciar o curso. Após a conclusão da graduação, a atuação na área contábil dos egressos aumentou consideravelmente passando de 27,03 para 63,51\%, isto demonstra que a graduação melhorou a posição dos egressos no mercado de trabalho e 36,49\% não atuam em sua área de formação.

Após a conclusão do curso os egressos enfrentaram dificuldades para ingressar no mercado de trabalho, foi constatado através da pesquisa que a maior dificuldade deve-se pela falta de e experiência e oportunidade. Levando em consideração que a classe dos contadores deixa a desejar quanto à remuneração um dos motivos para não seguir carreira em uma das varias áreas oferecidas pela contabilidade é devido ao baixo salário oferecido ao profissional.

Uma sugestão para o curso dada pelos entrevistados é investir mais no estagio durante o curso como forma de capacitar os universitários para o mercado de trabalho, colocá-los durante um período dentro de empresas real para conhecerem na prática a profissão a qual estão se formando. Sugerem também que a Instituição abra novos cursos de pós-graduação área contábil.

\section{REFERÊNCIAS}

ALBERTO. Valdemar Luiz Palombo. PERÍCIA CONTABIL. 3 ed. - São Paulo: Ed. Atlas, 2002 .

ALCAZAR, M. Palavras de ordem: integração, valorização, estímulos, aperfeiçoamento. Revista Brasileira de Contabilidade. no 178, 179 e 180. jul./dez. 2009.

ATTIE, William. Auditoria: conceitos e aplicações. 3 ed. São Paulo: Ed. Atlas, 1998.

BRITO, Márcia Regina F. de. O SINAES e o ENADE: da Concepção á implantação Avaliação (Campinas) vol.13 $\mathrm{n}^{\circ}$. 3 Sorocaba Nov. 2008. Disponivel em <http://www.scielo.br/scielo.php?pid=S1414-40772008000300014\&script=sci_arttext >. Acesso em 28 de Abril de 2012.

BOTH, Sérgio José, SIQUEIRA, Claudinete J. de Souza . Metodologia da pesquisa cientifica: teoria e prática ou prática à teoria. Tangará da Serra: Gráfica e Ed. Sanches Ltda., 2007.

CARNEIRO, Juarez Domingues, Regulamenta o Exame de Suficiência como requisito para obtenção ou restabelecimento de registro profissional em conselho regional de 
contabilidade (CRC) 2010. Disponível em:

<http://contabilidadepublica.wordpress.com/tag/exame-de-suficiencia/ > Acesso em 15 de setembro de 2012.

CAVALCANTE, C. H. L. Percepção dos alunos iniciantes e concluintes do curso de Ciências Contábeis sobre a profissão. Revista Brasileira de Contabilidade. $\mathrm{n}^{\circ}$ 177. mai./jun. 2009.

CREPALDI, Silvio Aparecido. Auditoria contábil teoria e prática. 2 ed. - São Paulo: Ed. Atlas, 2002.

CIÊNCIAS CONTÁBEIS - Fluxo discente. Disponível em:

$<$ http://tangara.unemat.br/contabeis/> Acesso em: 21 de março de 2012.

CRC: Conselho Regional de Contabilidade. Disponível em:

<http://www.crc.org.br/crcrj/crc.asp > Acesso em: 17 de março de 2012.

DEITOS, M. L. de S. A formação do profissional de Ciências Contábeis num contexto de permanente inovação nos processos produtivos. Revista Brasileira de Contabilidade. $\mathrm{n}^{\circ}$ 170. mar./abr. 2008.

DIAS, Lidiane Nazaré da silva, MOREIRA, Ana Carolina da Silva. As perspectivas da profissão contábil para os formandos em ciências contábeis do instituto de estudos superiores da Amazônia - Iesam. 2008. Disponível em

<http://www.ccontabeis.com.br/18cbc/482.pdf > . Acesso em 22 de abril de 2012.

DIAS, Dario Dal Col., RODRIGUES, Rubens Roberto, FERREIRA, Marcelo Marchine. Perfil do egresso do curso de ciências contábeis da FECILCAM. 2011 Disponível em: $<$ http://www.fecilcam.br/nupem/anais_vi_epct/PDF/ciencias_sociais/29.pdf $>$ Acesso em: 03 de março de 2012.

FIGUEIREDO, Sandra; FABRI, Pedro Ernesto. Gestão de empresas contábeis. São Paulo: Ed. Atlas S.A, 2000.

GIRARDI, Cristiane; Benchmarking educacional: estudo comparativo dos egressos do Curso de Ciências Contábeis da Universidade Federal de Santa Catarina e do Instituto de Ensino Superior da Grande Florianópolis. 2009. Disponivel em

<http://tcc.bu.ufsc.br/Contabeis291267>. Acesso em 03 de março de 2012.

IUDÍCIBUS, Sérgio de; MARION, José Carlos. Introdução à teoria da contabilidade para o nível e graduação. 3. Ed. - São Paulo: Atlas, 2002.

LEAL, Edvalda Araujo; SOARES, Mara Alves; SOUZA, Edileuza Godói de. Perspectivas dos formandos do curso de ciências contábeis e as exigências do mercado de trabalho. 2008. Disponível em: <http://dialnet.unirioja.es/servlet/articulo?codigo=3167057>. Acesso em: 19 de abril de 2012.

MARION, Jose Carlos Contabilidade empresarial. 11 ed. São Paulo: Ed. Atlas S.A, 2005.

MARION, José Carlos. Contabilidade empresarial. 15 ed.- São Paulo: Ed. Atlas S.A, 2009. 
MARION, José Carlos. Contabilidade rural: contabilidade agrícola, contabilidade da pecuária, imposto de renda pessoa jurídico. 7. ed. - São Paulo: Ed. Atlas, 2002.

MARION, José Carlos. O ensino da contabilidade. São Paulo: Ed. Atlas S.A, 1996.

ROSA, Maria Berenice. Contabilidade do setor público. São Paulo: Ed. Atlas, 2002.

SÁ, Antônio Lopes de. Teoria da contabilidade. - 3. ed. - São Paulo: Ed.Atlas, 2002.

SILVA, Antonio Carlos Ribeiro da. Metodologia da pesquisa aplicada à contabilidade. - 3 ed. - São Paulo: Ed. Atlas S.A - 2010.

SOCZEK, André Luiz Ribeiro. O perfil profissional dos egressos do curso de Ciências Contábeis da Unemat no mercado de trabalho. $23 \mathrm{f}$. Trabalho de Conclusão de Curso. Bacharel em Ciências Contábeis, Universidade do Estado de Mato Grosso, Tangará da SerraMT, 2010.

UNEMAT - Universidade do Estado de Mato Grosso, - Campus de Tangará da Serra-MT. Disponível em:<http://tangara.unemat.br $>$ Acesso em: 20 de março de 2012.

UNEMAT, - Universidade do estado de Mato Grosso - Histórico. Disponível em: <http://www.novoportal.unemat.br> Acesso em: 20 de março de 2012. 